\title{
INVERSE SCHEDULING IN FLOWSHOP WITH MULTIPLE MACHINES
}

\author{
Shrivatsa P. Aparanji \\ Research scholar, Department of Mechanical Engineering, \\ College of Engineering (A), Andhra University, Visakhapatnam, India
}

M. Srinivasa Rao

DGM (Maintenance), Department of MMSM, Visakhapatnam Steel Plant, India

V.V.S. Kesavarao

Professor, Department of Mechanical Engineering, College of Engineering(A), Andhra University, Visakhapatnam, India.

\begin{abstract}
In order to meet market requirements, operations to be performed with optimal sequence in scheduling systems and should allow enough flexibility against uncertain events to a specific objective. Traditional schedule will not address all these issues. In this paper, the inverse scheduling for multi machine flow shop with make span as objective is illustrated. Meta heuristics are applied to solve the problem six instances are adopted to verify the effectiveness of the proposed algorithm.
\end{abstract}

Key words: Inverse Scheduling, Flow Shop, Make Span, Heuristics.

Cite this Article: Shrivatsa P. Aparanji, M. Srinivasa Rao and V.V.S. Kesavarao, Inverse Scheduling in Flowshop with Multiple Machines, International Journal of Production Technology and Management (IJPTM), 10(1), 2019, pp. 19-42. http://iaeme.com/Home/issue/IJPTM?Volume=10\&Issue $=1$

\section{INTRODUCTION}

Scheduling is a decision-making process that concerns the allocation of limited resources to a set of tasks with the view of optimizing one or more objectives such as make span, flow time etc. In today's world of global competition, effective scheduling has become vital in order to meet customer requirements as promptly as possible while maximizing the profits. Scheduling in manufacturing systems is classically associated with scheduling a set of jobs on a set of machines in order to maximize the profit. Manufacturing system is classified as job shop, flow shop and open shop. A common $\mathrm{j}$ flow shop problem consists of $\mathrm{n}$ jobs $\{\mathrm{j} 1, \mathrm{j} 2, \mathrm{j} 3, \ldots, \mathrm{jn}\}$ to be processed through $\mathrm{m}$ machine $\{\mathrm{m} 1, \mathrm{~m} 2, \mathrm{~m} 3, \ldots, \mathrm{mm}\}$ to undergo operations. Technological constraints demand that each job should be processed through the machines in a particular order and gives a significant special case named as flow shop. The permutation 
flowshop scheduling problem consists of scheduling $\mathrm{n}$ independent and non preemptive jobs gathered in set $\mathrm{j}=\{1,2,3, \ldots, \mathrm{n}\}$ and $\mathrm{m}$ machines $=\{1,2,3, \ldots, \mathrm{m}\}$ all jobs should follow a fixed route of machines to be completed and due to the assumption, sequence of jobs on all machines are identical Flow shop scheduling problem with strong engineering background is an important optimization problem, which is of the difficulties such as inaccurate estimation of optimization objective and NP-hardness even small size problems are recognized to be NP hard problems (Pinedo, 2005).

In scheduling problems parameters are often deterministic and assumed to be known in advance. But in reality systems operate in highly dynamic and uncertain environments resulting from breakdowns, stoppages, change in market requirements, etc. this kind of uncertainty leads to complex scheduling environment.

In classical scheduling problems, machines are assumed to be available through the whole planning horizon, Machines may become unavailable during certain periods of planning horizon due to breakdown or preventive maintenance. There are some researches relaxing this unrealistic assumption, mainly the approach called machine scheduling with availability constraints where the number of preventive maintenance periods and their intervals are fixed and known in advance. The maintenance periods are incorporated into the constraints of the problem, with no change in the performance metric. In fact, the constraints are formulated in a way to plan the jobs in the available periods of time. Solution methodologies for such models range from traditional integer programming to complex heuristics.

The scheduling problems are combinatorial in nature. When solving an optimization problem of scheduling, the parameters such as costs, capacities, process etc. are assumed to be prior available and can be accurately predicted. However, in practice, it may happen that only estimates for the parameters are known. Only certain solutions are optimal. But in reality such situation does not exist. Hence there is a need for the research of alternate scheduling method. Therefore, in this paper, "inverse scheduling problem" (ISP) is applied to develop feasible practices for scheduling the manufacturing systems. The idea of inverse optimization is to find values of the parameters which make the known solutions optimum and which differ from the given estimates as little as possible. The main difference between the conventional scheduling problems and ISP is that the inverse scheduling assumes a pre- specific job sequence and expects to turn that sequence into an optimal one by minimally adjusting the job parameters.

The ISP eliminates or reduces scheduling conflicts by introducing flexibility in manufacturing. In addition, most research works just considered the single-machine inverse scheduling; very few papers paid attention to multiple machines. Unlike traditional optimization models for which all parameters are given and the objective is to find the optimal solution that satisfies special constraints.

Often in flow shop scheduling, finding optimized job sequence for minimization of make span is a difficult task. Heuristics can be employed to find the near optimal solution. In this thesis genetic algorithm is applied to find out the job sequence.

But in reality some time during the process we may encounter a situation, where in production may be forced to stop. This calls for rescheduling so as to maintain same make span by changing job sequence. If the sequence cannot be changed due to technological constraints only alternative is to compromise make span can be improved by adjusting process parameters (within a range) for same job sequence. Same thing can also be used at the start of schedule preparation when sequence is known.

In such situation inverse scheduling is helpful. Inverse scheduling is done by adjusting the process parameters (with in a range) and keeping the same job sequence and make span limit. In this thesis one such kind of problem is studied. 


\section{THE METHODOLOGY AS FOLLOWS}

More importantly, ISP may promote new ideas and developments in shop scheduling problem. In this paper, the main contributions of this paper can be summarized as

- formulation of an forward and inverse scheduling problem mathematically;

- calculation of optimum sequence for make span minimization problem;

- introducing controllable processing parameters to the traditional N-machine scheduling problem to consider a more realistic situation for most of the manufacturers for a given sequence to the optimum make span. Preventive maintenance periods and no. of preventive jobs are considered;

- usage of genetic algorithm to develop a meta heuristic algorithm for solving;

- assessing the quality of the algorithm and comparing it with tabu search algorithm.

- The ISP introduces significant improvements to the efficiency of manufacturing through eliminating or reducing scheduling conflicts.

\section{LITERATURE REVIEW}

\subsection{Brief review of inverse scheduling problem}

Inverse optimization problem (IOP) was first studied by Ahuja R. K. and Orlin, J. B. (2001) [1]. (Martorell et al., 2002) [2]. Martorell et al in their paper have studied on benefits and improvement areas in performing the coordinated optimization of TS \& M through reviewing the effectiveness and efficiency of common strategies for optimizing TS \& $\mathrm{M}$ at system level. (L. Wang and D.Z. Zheng, 2003) [3] proposed a heuristic for flow shop scheduling. They have said that in typical production scheduling problems, flow shop scheduling is one of the strongly NP-complete combinatorial optimization problems with a strong engineering background. Heuberger, C., (2004), Tarantola, A., (2005) [4] has been a hot research topic. The main difference between the conventional scheduling problems and ISP is that the inverse scheduling assumes a pre- specific job sequence and expects to turn that sequence into an optimal one by minimally adjusting the job parameters (Koulamas, 2005) [5]. Koulamas 2005 in his paper have concluded that Scheduling problems can be dealt with a view to sequence a list of jobs with the objective of minimizing some measurement of the job completion times. He also illustrated that Inverse problem can be simplified as linear programming problem The optimal solutions for minimization of total weighed completion time under different norms are obtained with mathematical tool for inverse scheduling on single machine by Chen et al. (2005) [6].

The relationship between the ISP and IOP is illustrated by Zhang J, and Longcheng Liu, (2006) [7] in their work have concluded that they considered that the inverse maximum flow problem under the weighted Hamming distance. Wang (2009), Liu L. and, Liu L.L [8] in their paper have concluded that the problem of scheduling jobs with equal processing times on a single batch processing machine so as to minimize a primary and a secondary criteria. $\mathrm{Ng}$, C.T. and Cheng, T.C.E. (2009) [9] in their work have said that in case of Optimization problems were concerned to find optimal solutions with respect to some objective function, e.g., costs, capacities, etc., given problem parameters and in many real-life situations only approximate values of the parameters were known, and a feasible solution was required. The single machine supply chain inverse problem and flowshop scheduling with two machines were brought out by Chen and Tang (2009) [9]. The problems of scheduling can be formulated and solved involving different controllable parameters by Chen and Tang (2009) [9]. The inverse scheduling is defined by Brucker, P. and Shakhlevich, N.V. (2009) [10], the single-machine inverse and reverse scheduling problem, are also mentioned by them. PM 
aims to reduce the chance of any unexpected failures. Berrichi et al. (2009) [11] have presented the simultaneous scheduling of both production and maintenance activities. In some scheduling shop, processing times can be changed on few jobs, i.e., speeding up some of them or slowing down others, so that the initial sequences wass optimal as illustrated by Fattahi P. and Fallahi, A. 2010) [12].

Moradi and Zandieh (2010) [13] investigated the make span and the system unavailability problem and presented a genetic algorithm for the problem. The necessary and sufficient conditions of optimality of a solution which was obtained in flowshop ISP (Brucker, P. and Shakhlevich, N.V., 2011) [14]. Pham and Lu (2012) [15] also suggested methods for the inverse scheduling problem on identical parallel machines. Preventive maintenance (PM) is defined as a set of activities aimed at improving the overall reliability and availability of a system (Ahmad and Kamaruddin, 2012) [16]. Hence calculated optimal schedule may not be optimal and even some times infeasible (Vanderpooten, D P 2010 and Kasperski, A., Kurpisz, A., and Zielinski, Aissi 2012, H., Bazgan C.) [17]. Ganesan, T., et al. (2013) [18] in their paper have developed an empirical model suitable for chemical industry. Zielinski, P., (2012), Aissi H., Bazgan C] [17], have concluded that the preplanned job sequence cannot be changed arbitrarily due to technological or process constraint. Vasant, P. (2013) [19] in his work have concluded that the fuzzy optimization problem is one of the prominent topics in the broad area of artificial intelligence. The common thing observed is formulation of linear programming in these papers. Many research works are observed on single-machine problem (e.g., Kim B. S. and. Joo C. M, 2011 Liu, P.) [20] in their paper, they studied a single-machine scheduling problem with deteriorating processing time of jobs and multiple rate-modifying activities which reset deteriorated processing time to the original processing time. In this situation, the objective function is to minimize total completion time. Tian X., (2013) [21] in his paper have considered several two-agent scheduling problems with resource consumption on a single machine, where each of the agents wants to minimize a measure dependent on its own jobs. Li D.-C., Hsu P.H., and. Chang C.C., 2014) [22] in their work have concluded that the way to gain knowledge and experience of producing a product in a firm can be seen as new solution for reducing the unit cost in scheduling problems, which is known as "learning effects". (Hongtruong, P. and Xiwen, L., 2014) [23] for ISP to find the optimal solution. Hongtruong, P. and Xiwen, L., (2014) in their paper have concluded that in inverse scheduling problems, a job sequence is given and the objective is to determine the minimal perturbation to parameters, such as processing times or weights of jobs so that the given schedule becomes optimal with respect to a pre-selected objective function. Wang and Liu (2014) [24] in their work have investigated an integrated biobjective optimization problem with non-resumable jobs for production scheduling and preventive maintenance in a two-stage hybrid flow shop with one machine on the first stage and $m$ identical parallel machines on the second stage. Cui et al. (2014) [25] in their work have concluded that the problem of finding robust production and maintenance schedules for a single machine with failure uncertainty. Hassene Aissi, et al. (2010) [17] in their work have stated that while the complexity of min_max and min_max regret versions of most classical combinatorial optimization problems has been thoroughly investigated, there are very few studies about their approximation Batun, S., et al. (2009) [26] in their work have considered the single machine total flow time problem in which the jobs are non-resumable and the machine is subject to preventive maintenance activities of known starting times and durations. Elamvazurthi, et al. (2013) [27] in their work stated that the fuzzy technology reveals that everything was a matter of degree. The prime objective of their work was to investigate a new application to the literature and to solve the crude oil refinery production problem by using the hybrid optimization techniques such as; Tabu Search (TS), Hopfield Recurrent Artificial Neural Network (HRANN) and fuzzy approaches. In their work, the real-world problem of the refinery model (which has been 
developed in (Gunes, 2000)) was solved using various optimization techniques. Glover, F. (1989) [28] in his work have presented that the fundamental principles underlying tabu search as a strategy for combinatorial optimization problems. Reeves, C. (1995) [29] in his paper titled "A genetic algorithm for flow shop sequencing" have discussed the basic concepts of Genetic Algorithms, following which a Genetic Algorithm was developed for finding (approximately) the minimum make span of the $n$-job, m-machine permutation flow shop sequencing problem Wang, L.Z. (2009) [30] in his work has presented cutting plane algorithms for the inverse mixed integer linear programming problem (InvMILP), which was to minimally perturb the objective function of a mixed integer linear program in order to make a given feasible solution optimal.

\subsection{Limitations of current researches}

Linear programming algorithm and mixed integer programming is generally used in solving ISP. Minimization of makespan, tardiness etc. are the common criteria that are generally considered in scheduling models.

- Most of the papers on ISP just considers one single objective the reason may be the single-machine problem is easier to treat than the multiple machine problems. Though real-life situations are not simpler.

- Early papers focused on linear programming as simple, small-scale problems are dealt Meta heuristics only can be used to solve large-sized problems.

Therefore, there is still a scope for the research about ISP on multi machine environment using heuristics.

\subsection{Assumptions made in the paper}

The inverse scheduling problem assumes that a given feasible solution (schedule sequence) is definite and the job parameters are controllable. The objective is to determine the minimal perturbation (e.g., mainly processing times, due dates or their weights if any) so that the defined job sequence remains same and solution becomes near optimal (schedule). In this paper, an inverse scheduling problem is considered under a multi-machine environment with the minimization of completion time.

Thus, the optimization objective of the ISP is to minimize the adjustment of the process parameters $(\|p-p\|)$. It is assumed and needs to be minimally adjusted so that a pre specific schedule becomes an optimal one. Formally $i(i=1,2, \ldots, n)$ are the decision variables. It is important to note that the resulting make span based on the adjusted parameters is no greater than the total make span time based on the original parameters. In solving his problem, several constraints and assumptions are made as follows.

- Each machine could process at most one job at a time.

- All jobs are available from the beginning.

- No precedence constraints among the jobs.

- The machines are always available at beginning (time zero) and needs maintenance at selected intervals.

- Processing time of all jobs are known.

- Due dates are fixed and processing time is determined

- The given job sequence is fixed.

- The given job sequence is a feasible schedule not the most optimal one. 


\section{NOTATIONS}

Let $i$ be job index, $j$ be machine index and represent job priority index. It is supposed that $i$ $[1,2,3, \ldots, n]$ is the set of jobs, which have to be processed in $m$-machine flow shop environment. Jobs are independent of each other.

The objective function is to minimize expected makespan.

The applied symbols are as follows:

In between $\mathrm{n}$ jobs say some are maintenance jobs to be carried out on machines Set of maintenance jobs
$x_{i k}=$
1 if job $i$ has the priority of $k$; otherwise 0
$p_{j i}=$ processing time of job $i$ on machine $j$
$\mathrm{c}_{\max }=$ completion time of job with priority $n$ on machine $m$, last job
$c_{m i}=$ completion time on machine $\mathrm{m}$ for the job i position
$s_{m k}=$ start time on machine $\mathrm{m}$ for the job in $\mathrm{k}$ th position
$t_{i}=$ time for maintenance. On machine $\mathrm{i}$
$Z_{i k}=$ 1 if machine $\mathrm{i}$ is taken up for maintenance after kth position job or else 0 .
$p m_{r}=$ maximum no. of preventive maintenance activities.

\subsection{Objective function}

$\min \mathrm{z}=\min \mathrm{c}_{\mathrm{mn}}$

(Last job $n$ on machine $m$ ) +

Subject to

Each job shall have unique priority

$\sum_{i=1}^{n} x_{i k}=1$

$$
\begin{aligned}
& \text { for } k=1,2,3, \ldots, n \\
& \text { for } I=1,2,3, \ldots, n
\end{aligned}
$$

$\sum^{n} \quad x_{i k}=1$

$k=1$

(Ensures one job in one position)

Start time of jobs first priority on machine 1 in sequence.

$s_{m 1 k 1}=0$

for explanation $i$ have changed the equation with machine 1 and priority $k 1$.

Start time of other jobs on first machine +maintenance period

$$
s_{\mathbf{1} k}+\sum_{=\mathbf{1}}^{n} p_{\mathbf{1}} x_{i k}+Z_{\mathbf{1} k}{ }^{*} t_{\mathbf{1}}=s_{\mathbf{1}, k+\mathbf{1}} \quad \text { (for } k=1,2,3, \ldots, n-1 \text { ) }
$$

Start time of first job on all other machines say machine 2 , machine 3 etc. ensures that the starting time of each job on machine $r+1$ is not earlier than its finishing time on machine $r$.

$$
\begin{array}{ll}
s_{r \mathbf{1}}+\sum_{=\mathbf{1}}^{n} p_{r i} x_{i \mathbf{1}}=s_{r+\mathbf{1}, \mathbf{1}} & (\text { for } r=1,2,3, \ldots, m-1) \\
s_{r k}+\sum_{=\mathbf{1}}^{n} p_{r i} x_{i k} \quad \leq s_{r+\mathbf{1}, k} & (\text { for } r=1,2,3, \ldots, m-1)(\text { for } k=1,2,3, \ldots, n)
\end{array}
$$

Ensures that the job in the sequence position $k+1$ does not start on machine $r$ until the job in position $k$ in the sequence has completed its processing on that machine, and the maintenance activity on position $k$ is performed, if it is planned $\left(Z_{r k}=\mathbf{1}\right)$.

$$
\left.\left.s_{r k}+\sum_{=1}^{n} p_{r i} x_{i k}+Z_{r k}{ }^{*} t_{r} \leq s_{r, k+1} \quad \text { (for } r=1,2,3, \ldots, m\right) \text { for } k=1,2,3, \ldots, n-1\right)
$$

Ensures that the number of maintenance activities performing on machine $r$ is no more than $p m_{r}$.

$$
\left.\sum_{k=1}^{n} Z_{r k} \leq p m_{r} \quad \text { (for } r=1,2,3, \ldots, m\right)
$$


Completion time of job $i$ on last machine $m$ is

$$
c_{m i}=s_{m i}+\sum_{k=1} p_{m i} x_{i k} \quad \text { for all } i \text { jobs }
$$

Due date shall be grater than completion date to meet dead line

$$
c_{m i} \leq \text { duedate }_{i}
$$

$Z_{m k}=$ zero; (after last job on each machine, maintenance activity need not be considered)

completion time of last job on last machine $=c_{m n}$.

$$
c_{m n}=s_{m n}+\sum_{=1}^{n} p_{m i} x_{i n}
$$

\subsection{Inverse scheduling}

Under $l_{\mathbf{1}}$ (Manhattan norm i.e., Manhattan distance is a distance metric between two points in a $\mathrm{N}$ dimensional vector space. It is the sum of the lengths of the projections of the line segment between the points onto the coordinate axes. In simple terms, it is the sum of absolute difference between the measures in all dimensions of two points. It is also known as L1 norm and L1 metric, the inverse problem (as described by Brucker) can be written as follows for single machine, i.e., minimizing the sum of absolute deviations of process

parameters Min $\sum_{j=\mathbf{1}}^{n}\left|\hat{p}_{j}-p_{j}\right|$, where $\hat{p}_{j} \varepsilon\left[p_{j}, \bar{p}\right]$ for $\mathrm{j} \varepsilon$. Number of jobs where $\underline{p}_{j},{ }^{p} p \mathfrak{a}$ upper and lower limits of processing parameters.

It is extended as follows for the given target sequence. i.e. $(1,2,3, \ldots, n)$ to make it optimal by minimizing the sum of absolute deviations of process parameters Keeping maintenance duration same.

$$
\text { Objective function }=\operatorname{Min} \sum_{m=\mathbf{1}}^{m} \sum_{j=\mathbf{1}}^{n}\left|\hat{p}_{j m}-p_{j m}\right| \text { Where } \hat{p}_{j m} \varepsilon\left[p_{j m}, \bar{p}_{h}\right] \text { for } \mathrm{j} \varepsilon
$$

Number of jobs $m$ for machines. $\hat{p}_{j m} p_{j m}, p_{n}$ are adjusted process parameter, lower htof process parameter and upper process parameter respectively the inverse problem has to be solved keeping all other constraints same excepting target sequence which is the outcome of forward scheduling, and $c_{m n} \leq \mathrm{Z}$ (make span of forward scheduling).

\subsection{Hybrid algorithm of the flowshop problem:}

The steps followed in solving flow shop problem

- Minimized Make span is obtained through genetic algorithm in forward scheduling. Job sequence is obtained chromosome selected for GA is permuted job sequence.

- The sequence obtained above is taken as input for inverse scheduling. Process parameters are adjusted by minimizing the sum of deviation of process parameters without increasing the make span. Here chromosome selected is process speed of job sequence of forward scheduling.

- Finally the adjusted processing speeds are determined with improvement in make span using the GA.

- Same experiment is conducted with tabu search in inverse scheduling and results are compared. 


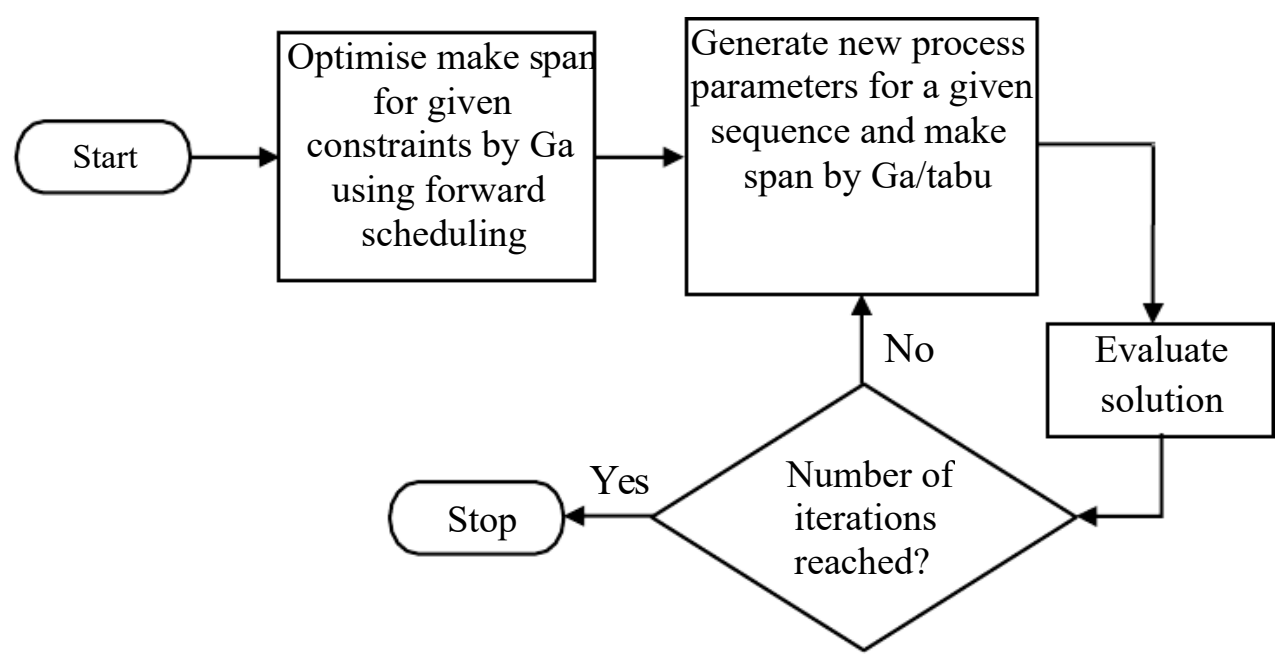

\subsection{Forward scheduling}

Sequence of algorithm

- Identification Feasible sequences of 4 numbers initially

- 4 Nos. of best sequences are taken for crossover

- Calculation of fitness function

- Store all best feasible sequences max 10 numbers (population size)

- Perform step 2, 3, 4 for 10 times

- Perform mutation

- Perform step 4 and step 5

- Perform step 6 followed by step 7 for 3 times

- Stop

Furnish best sequence.

Forward scheduling objective

Fitness function $=$ minimization of makespan

(total jobs are counted as 6)

$\mathrm{Ga}=$ Representation of job (chromosome).

\begin{tabular}{|c|c|c|c|c|c|}
\hline Job no say (1) & 2 & 5 & 4 & 3 & 6 \\
\hline 00000001 & 000000010 & 00000101 & 00000100 & 00000011 & 00000111 \\
\hline
\end{tabular}

Cross over:

Parent 1

\begin{tabular}{|l|l|l|l|l|l|}
\hline 1 & 2 & 5 & 4 & 3 & 6 \\
\hline
\end{tabular}

Parent 2

\begin{tabular}{|l|l|l|l|l|l|}
\hline 1 & 2 & 4 & 5 & 3 & 6 \\
\hline
\end{tabular}

Child 1

\begin{tabular}{|l|l|l|l|l|l|}
\hline 1 & 2 & 4 & 5 & 3 & 6 \\
\hline
\end{tabular}




\section{Child 2}

\begin{tabular}{|l|l|l|l|l|l|}
\hline 1 & 2 & 5 & 4 & 3 & 6 \\
\hline
\end{tabular}

Total chromosomes 4:

Best 4 selected and and cross over is done.

After 10 iterations mutation is conducted.

Mutation example:

\begin{tabular}{|l|l|l|l|l|l|}
\hline 1 & 2 & 5 & 4 & 3 & 6 \\
\hline
\end{tabular}

- Randomly one position is selected say 2

- The job is changed randomly in between 1 to 6 , say new job has become 4 .

New sequence

\begin{tabular}{|l|l|l|l|l|l|}
\hline 1 & 4 & 5 & 4 & 3 & 6 \\
\hline
\end{tabular}

Now as the job 4 is repeated twice job 4 is which is not changed till now is change to 2 .

New sequence

\begin{tabular}{|l|l|l|l|l|l|}
\hline 1 & 4 & 5 & 2 & 3 & 6 \\
\hline
\end{tabular}

\subsection{Inverse scheduling}

Fitness function $=$ minimization of deviations of process times.

Sequence of algorithm:

- Identification feasible sequences of 4 numbers initially

- 4 Nos. of best sequences are taken for crossover

- Calculation of fitness function

- Store all best feasible sequences max 10 numbers

- Perform step 2, 3, 4 for 10 times

- Perform mutation

- Perform step 4 and step 5

- Perform step 6 followed by step 7 for 3 times

- Stop.

Furnish best sequence.

Identification Feasible sequences of 4 numbers initially:

\begin{tabular}{|l|c|c|c|c|}
\hline Normal jobs & 1 & 2 & 3 & 4 \\
\hline Machine 1 & 5 & 7 & 4 & 8 \\
\hline Machine 2 & 3 & 4 & 5 & 4 \\
\hline Due date & 20 & 20 & 28 & 30 \\
\hline
\end{tabular}

Machine 1 maintenance 2 hrs, no. of times 1; machine 2 maintenance $3 \mathrm{hrs}$, no. of times 1 .

$1^{\text {st }}$ job on machine 1 :

Start time $=0$

Finish time $=0+5=5$

$2^{\text {nd }}$ job on machine 1 :

Start time $=5$

Finish time $=5+7=12$

Machine 1 maintenance starts $=12$

Machine maintenance finish time: Finish time $=12+2=14$

$3^{\text {rd }}$ job on machine 1

start time $=14$

Finish time $=14+4=18$ 
$4^{\text {th }}$ job on machine 1

$4^{\text {th }}$ job on machine 1

$1^{\text {st }}$ job on machine 2

$1^{\text {st }}$ job completion time

$2^{\text {nd }}$ job on machine 2

$2^{\text {nd }}$ job on machine 2

Machine 2 maintenance

Machine 2 maintenance

$3^{\text {rd }}$ job starts on machine 2

( since $3^{\text {rd }}$ job on $\mathrm{m} / \mathrm{c}$ completes at 18 , machine 2 free at 19)

$3^{\text {rd }}$ job on $\mathrm{m} / \mathrm{c} 2$ Finishes $(19+5)=24$

$4^{\text {th }}$ job on $\mathrm{m} / \mathrm{c} 2$ Start time $=24$

$4^{\text {th }}$ job on $\mathrm{m} / \mathrm{c} 2$ finish time $=24+4=28$

\begin{tabular}{|l|l|l|l|l|}
\hline Normal jobs & $\mathbf{1}$ & $\mathbf{2}$ & $\mathbf{3}$ & $\mathbf{4}$ \\
\hline Machine 1 & 6 & 8 & 5 & 7 \\
\hline Machine 2 & 4 & 3 & 4 & 5 \\
\hline Due date & 20 & 20 & 28 & 30 \\
\hline
\end{tabular}

Machine 1 maintenance 2 hrs, no. of times 1; machine 2 maintenance $3 \mathrm{hrs}$, no. of times 1 say sequence 1,2,3,4 (second iteration)

$1^{\text {st }}$ job on machine 1

Start time $=0$

Finish time $=0+6=6$

$2^{\text {nd }}$ job on machine 1

Start time $=6$

Finish time $=6+8=14$

Machine 1 maintenance

Starts $=14$

Machine maintenance

$3^{\text {rd }}$ job on machine one

Finish time finish time $=14+2=16$

start time $=16$

Finish time $=16+5=21$

$4^{\text {th }}$ job on machine 1

Start time $=21$

Finish time $21+7=28$

$1^{\text {st }}$ job on machine 2

Start time $=6$

$1^{\text {st }}$ job completion time on $\mathrm{m} / \mathrm{c} 2=6+4=10$

$2^{\text {nd }}$ job on machine 2

Start time $=14$

Finish time $=14+3=17$

Machine 2 maintenance

Starts $=17$

Machine 2 maintenance

$3^{\text {rd }}$ job starts on machine 2

Finishes $=17+3=20$

Start time $=20$

( since $3^{\text {rd }}$ job on $\mathrm{m} / \mathrm{c} 1$ completes at 21 , machine 2 free at 20)

$3^{\text {rd }}$ job on machine 2

Finishes $21+4=25$ 
$4^{\text {th }}$ job on machine 2

Start time $=25$

$4^{\text {th }}$ job on machine 2

Finish time $=25+5=30$

\begin{tabular}{|c|c|c|c|}
\hline Job list & Initial & Changed value & Deviation \\
\hline $1^{\text {st }}$ job on machine 1 & 5 & 6 & 1 \\
\hline $2^{\text {nd }}$ job on machine 1 & 7 & 8 & 1 \\
\hline $3^{\text {rd }}$ job on machine 1 & 4 & 5 & 1 \\
\hline $4^{\text {th }}$ job on machine 1 & 8 & 7 & 1 \\
\hline $1^{\text {st }}$ job on machine 2 & 3 & 4 & 1 \\
\hline $2^{\text {nd }}$ job on machine 2 & 4 & 3 & 1 \\
\hline $3^{\text {rd }}$ job on machine 2 & 5 & 4 & 1 \\
\hline $4^{\text {th }}$ job on machine 2 & 4 & 5 & 1 \\
\hline
\end{tabular}

Total deviations $=8$

Best aspiration $=8$

$3^{\text {rd }}$ sequence

\begin{tabular}{|c|c|c|}
\hline Job Sl. No. & Machine location & Processing speed \\
\hline 1 & 1 & 7 \\
\hline 2 & 1 & 9 \\
\hline 3 & 1 & 6 \\
\hline 4 & 1 & 9 \\
\hline 1 & 2 & 5 \\
\hline 2 & 2 & 6 \\
\hline 3 & 2 & 5 \\
\hline 4 & 2 & 6 \\
\hline
\end{tabular}

$1^{\text {st }}$ job on machine 1

Start time $=0$

finish time $=0+7=7$

$1^{\text {st }}$ job on machine 2

Start time $=7$

$1^{\text {st }}$ job completion time on machine $2=7+5=12$

$2^{\text {nd }}$ job on machine 1

Start time $=7$

Finish time $=7+9=16$

$2^{\text {nd }}$ job on machine 2

Start time $=16$

$2^{\text {nd }}$ job on machine 2

Finish time $=16+6=22$

Machine 1 maintenance

Starts $=16$

Machine 1 maintenance

Finish time $=16+2=18$

$3^{\text {rd }}$ job on machine one

Start time $=18$

$3^{\text {rd }}$ job on machine one

Finish time $=18+6=24$

Machine 2 maintenance

Starts $=22$

Machine 2 maintenance

Finishes $=22+3=25$

$3^{\text {rd }}$ job on machine 2

Start time $=25$

$3^{\text {rd }}$ job on machine 2

Finishes $25+5=30$

$4^{\text {th }}$ job on machine 1 start time $=3^{\text {rd }}$ job on machine one finish time $=24$

$4^{\text {th }}$ job on finish time on machine $1=24+9=33$

$4^{\text {th }}$ job on machine 2

start time $=3^{\text {rd }}$ job on machine 2 finishes $=33$

$4^{\text {th }}$ job on machine 2

finish time $=33+6=39$ 
Make span $=39$

Aspiration criteria

Sum of process deviation

\begin{tabular}{|c|c|c|c|}
\hline Job list & Initial & Changed value & Deviation \\
\hline $1^{\text {st }}$ job on machine 1 & 5 & 7 & 2 \\
\hline $2^{\text {nd }}$ job on machine 1 & 7 & 9 & 2 \\
\hline $3^{\text {rd }}$ job on machine 1 & 4 & 6 & 2 \\
\hline $4^{\text {th }}$ job on machine 1 & 8 & 9 & 1 \\
\hline $1^{\text {st }}$ job on machine 2 & 3 & 5 & 2 \\
\hline $2^{\text {nd }}$ job on machine 2 & 4 & 6 & 2 \\
\hline $3^{\text {rd }}$ job on machine 2 & 5 & 5 & 0 \\
\hline $4^{\text {th }}$ job on machine 2 & 4 & 6 & 2 \\
\hline
\end{tabular}

Total deviation $=13$

Aspiration 13

$4^{\text {th }}$ sequence

\begin{tabular}{|c|c|c|}
\hline Job Sl. No. & Machine location & Processing speed \\
\hline 1 & 1 & 6 \\
\hline 2 & 1 & 9 \\
\hline 3 & 1 & 6 \\
\hline 4 & 1 & 9 \\
\hline 1 & 2 & 6 \\
\hline 2 & 2 & 5 \\
\hline 3 & 2 & 5 \\
\hline 4 & 2 & 5 \\
\hline
\end{tabular}

$1^{\text {st }}$ job on machine 1

Start time $=0$

Finish time $=0+6=6$

$1^{\text {st }}$ job on machine 2

Start time $=6$

$1^{\text {st }}$ job completion time on machine $2=6+6=12$

$2^{\text {nd }}$ job on machine 1

Start time $=6$

Finish time $=6+9=15$

$2^{\text {nd }}$ job on machine 2

Start time $=15$

$2^{\text {nd }}$ job on machine 2

Finish time $=15+5=20$

Machine 1 maintenance

Starts $=15$

Finish time $=15+2=17$

$3^{\text {rd }}$ job on machine one

Start time $=17$

$3^{\text {rd }}$ job on machine one

Finish time $=17+6=23$

Machine 2 maintenance

Starts $=20$

Machine 2 maintenance

Finishes $=20+3=23$

$3^{\text {rd }}$ job on machine 2

Start time $=23$

$3^{\text {rd }}$ job on machine 2

Finishes $23+5=28$

$4^{\text {th }}$ job on machine 1 start time $=3^{\text {rd }}$ job on machine one finish time $=23$

$4^{\text {th }}$ job on finish time on machine $1=23+9=32$

$4^{\text {th }}$ job on machine 2

Start time $=3^{\text {rd }}$ job on machine 2 finishes $=32$

$4^{\text {th }}$ job on machine 2

Finish time $=32+5=37$ 
Make span $=37$

Aspiration criteria

Sum of process deviation

\begin{tabular}{|l|c|c|c|}
\hline Job list & Initial & Changed value & Deviation \\
\hline $1^{\text {st }}$ job on machine 1 & 5 & 6 & 1 \\
\hline $2^{\text {nd }}$ job on machine 1 & 7 & 9 & 2 \\
\hline $3^{\text {rd }}$ job on machine 1 & 4 & 6 & 2 \\
\hline $4^{\text {th }}$ job on machine 1 & 8 & 9 & 1 \\
\hline $1^{\text {st }}$ job on machine 2 & 3 & 6 & 3 \\
\hline $2^{\text {nd }}$ job on machine 2 & 4 & 5 & 1 \\
\hline $3^{\text {rd }}$ job on machine 2 & 5 & 5 & 0 \\
\hline $4^{\text {th }}$ job on machine 2 & 4 & 5 & 1 \\
\hline
\end{tabular}

Total deviation $=11$

Fitness value aspiration 11

Other sequences are done in similar fashion.

Cross over

Sequence 1

\begin{tabular}{|l|l|l|l|l|l|l|l|}
\hline 5 & 7 & 4 & 8 & 3 & 6 & 5 & 4 \\
\hline
\end{tabular}

Sequence 2

\begin{tabular}{|l|l|l|l|l|l|l|l|}
\hline 6 & 8 & 5 & 7 & 5 & 3 & 4 & 5 \\
\hline
\end{tabular}

Representation in binary code:

\begin{tabular}{|l|l|l|l|l|l|l|l|}
00000101 & 00000111 & 00000100 & 00001000 & 00000011 & 00000110 & 00000101 & 00000100 \\
\hline
\end{tabular}

\begin{tabular}{|l|l|l|l|l|l|l|l|}
\hline 00000110 & 00001000 & 00000101 & 00000111 & 00000101 & 00000011 & 00000100 & 00000101 \\
\hline
\end{tabular}

ross over at third point in each cell:

\begin{tabular}{|l|l|l|l|l|l|l|l|}
\hline 00000110 & 00000100 & 00000101 & 00001011 & 00000001 & 00000111 & 00000100 & 00000101 \\
\hline
\end{tabular}

\begin{tabular}{|l|l|l|l|l|l|l|l|}
000000101 & 00001011 & 00000100 & 00000100 & 00000111 & 00000010 & 00000101 & 00000100 \\
\hline
\end{tabular}

Conversion to digital code:

Child 1

\begin{tabular}{|c|c|c|c|c|c|c|c|}
\hline 6 & 4 & 5 & 10 & 1 & 6 & 6 & 5 \\
\hline 5 & 11 & 4 & 4 & 7 & 2 & 5 & 4 \\
\hline
\end{tabular}

Mutation example:

Sequence

\begin{tabular}{|l|l|l|l|l|l|l|l|}
\hline 7 & 9 & 6 & 6 & 5 & 6 & 5 & 6 \\
\hline \multicolumn{8}{|c|}{ Conversion to binary }
\end{tabular}

\begin{tabular}{|l|l|l|l|l|l|l|l|}
\hline 00000111 & 00001001 & 00000110 & 00000110 & 00000101 & 00000110 & 00000110 & 00000110 \\
\hline
\end{tabular}

Randomly chrome some cell is selected and one bit among (1-4) in string is randomly changed to other binary digit. 
Say in this third cell is bit changed to 1 .

\begin{tabular}{|l|l|l|l|l|l|l|l|}
\hline 00000111 & 00001001 & 00000110 & 00000111 & 00000101 & 00000110 & 00000110 & 00000110 \\
\hline
\end{tabular}

New values becomes

\begin{tabular}{|l|l|l|l|l|l|l|l|}
\hline 7 & 9 & 6 & 7 & 5 & 6 & 5 & 6 \\
\hline
\end{tabular}

\subsection{Applying Tabu search}

- Initialization: The process speeds of jobs for the same job sequence is taken as input.

- One more sequence is generated with processing speeds selected randomly.

- Intensification phase: The processing speeds of each job in the best sequence is changed taking into consideration the processing speed of jobs in next best available sequence one at a time for determination of objective function.

- The intensification process is repeated for predetermined iterations. After $\mathrm{n}$ iterations diversification phase is performed.

- Diversification phase: To drive the unexplored regions uniformly and to avoid local optimum a diversification strategy is included.

- The intensification phase results are placed in short term memory and diversification phase results are stored in long term memory. The tabu list is updated by first in first out in order to improve the search space job sequence is accepted when the aspiration level is greater than certain threshold value even if it is lesser than best objective value is reached so far.

- Termination criteria: The iteration stops when the visits from diversification phase to intensification reaches set number of times.

- No of iterations:

Intensification phase $=10 *$ number of jobs

Diversification phase $=5^{*}$ number of jobs

Termination criteria $=10^{*}$ number of jobs

\subsection{Tabu algorithm}

Step-1:

Select the feasible sequence say 1, 2, 3, 4 with original speeds calculate make span.

Select second sequence of 1, 2, 3, 4 with another processing speeds (by changing process speeds within range randomly) calculate make span function.

Calculate sum of process deviation of second sequence.

Best 1 (aspiration criteria) $=$ sum of process deviation, and store it.

Diversification phase-counter $=0$

Step-2: Initiate tabu condition: randomly say tabu = machine 2, job 3 speed

Step-3: Perform intensification phase.

- Generation of different processing speed except tabu calculation of aspiration criteria.

- Perform the same for say 7 times.

- Generation of different processing speed with tabu for one time. calculation of aspiration criteria.

- If the aspiration criteria is acceptable that is better than the best accept the sequence with new speeds.

- Select the best among them and store .and increment the tabu 1 counter by 1 .

- Perform step 2. Tabu $2=$ machine 3, job 3. Perform $a$ to $e$ and increment tabu 2 counter by 1 .

- Perform step 2. Tabu $3=$ machine 3, job 2. Perform $a$ to $e$ and increment tabu 3 counter by 1 . 
- Let tabu 2 will become tabu 1 and tabu 3 will become tabu $2=2$. And initiate tabu $3=0$;

- Always maintain counter to know no. of times tabu 1 changes. If it is changed say 8 times, Increment Diversification phase-counter by 1 . Perform step 4.

Step-4: If the Diversification phase-counter is 5 perform step 5.

Else perform the Diversification phase.

Calculate aspiration criteria $f$ it is best store it.

Perform step 3.

Step-5: The best aspiration value and its speeds are the answer.

\begin{tabular}{|l|c|c|c|c|}
\hline Normal jobs & $\mathbf{1}$ & $\mathbf{2}$ & $\mathbf{3}$ & $\mathbf{4}$ \\
\hline Machine 1 & 5 & 7 & 4 & 8 \\
\hline Machine 2 & 3 & 4 & 5 & 4 \\
\hline Due date & 20 & 20 & 28 & 30 \\
\hline
\end{tabular}

Machine 1 maintenance 2 hrs, no. of times 1; machine 2 maintenance $3 \mathrm{hrs}$, no. of times 1 .

Step-1: Say sequence 1, 2, 3, 4.

$1^{\text {st }}$ job on machine 1

Start time $=0$

Finish time $=0+5=5$

$2^{\text {nd }}$ job on machine 1

Start time $=5$

Finish time $=5+7=12$

Machine 1 maintenance starts $=12$

Machine maintenance finish time $=12+2=14$

$3^{\text {rd }}$ job on machine 1

Start time $=14$

Finish time $=14+4=18$

$4^{\text {th }}$ job on machine 1

Start time $=18$

Finish time $18+8=26$

$1^{\text {st }}$ job on machine 2

Start time $=5$

$1^{\text {st }}$ job completion time on machine $2=5+3=8$

$2^{\text {nd }}$ job on machine 2

Start time $=12$

$2^{\text {nd }}$ job on machine 2

Finish time $=12+4=16$

Machine 2 maintenance

Starts $=16$

Machine 2 maintenance

Finishes $=16+3=19$

$3^{\text {rd }}$ job starts on machine 2

Start time $=19$

( since $3^{\text {rd }}$ job on machine completes at 18 , machine 2 free at 19)

$3^{\text {rd }}$ job on machine 2

Finishes $(19+5)=24$

$4^{\text {th }}$ job on machine 2

Start time $=24$

$4^{\text {th }}$ job on machine 2

Finish time $=24+4=28$

\begin{tabular}{|l|c|c|c|c|}
\hline Normal jobs & $\mathbf{1}$ & $\mathbf{2}$ & $\mathbf{3}$ & $\mathbf{4}$ \\
\hline Machine 1 & 6 & 8 & 5 & 7 \\
\hline Machine 2 & 4 & 3 & 4 & 5 \\
\hline Due date & 20 & 20 & 28 & 30 \\
\hline
\end{tabular}


Machine 1 maintenance 2 hrs, no. of times 1; machine 2 maintenance 3 hrs, no. of times 1 . say sequence 1, 2, 3, 4 (second iteration)

$1^{\text {st }}$ job on machine 1

$2^{\text {nd }}$ job on machine 1

Machine 1 maintenance

Machine 1 maintenance

$3^{\text {rd }}$ job on machine 1

$4^{\text {th }}$ job on machine 1

$1^{\text {st }}$ job on machine 2

$1^{\text {st }}$ job completion time

$2^{\text {nd }}$ job on machine 2

$2^{\text {nd }}$ job on machine 2

Machine 2 maintenance

Machine 2 maintenance
Start time $=0$

Finish time $=0+6=6$

Start time $=6$

Finish time $=6+8=14$

Starts $=14$

Finish time $=14+2=16$

Start time $=16$

Finish time $=16+5=21$

Start time $=21$

Finish time $21+7=28$

Start time $=6$

$3^{\text {rd }}$ job starts on machine 2 start time $=20$

( since $3^{\text {rd }}$ job on machine 1 completes at 21 , machine 2 free at 20)

$3^{\text {rd }}$ job on machine 2

Finishes $21+4=25$

$4^{\text {th }}$ job on machine 2

Start time $=25$

$4^{\text {th }}$ job on machine 2

Finish time $=25+5=30$

Sum of process deviation

\begin{tabular}{|c|c|c|c|}
\hline Job list & Initial & Changed value & Deviation \\
\hline $1^{\text {st }}$ job on machine 1 & 5 & 6 & 1 \\
\hline $2^{\text {nd }}$ job on machine 1 & 7 & 8 & 1 \\
\hline $3^{\text {rd }}$ job on machine 1 & 4 & 5 & 1 \\
\hline $4^{\text {th }}$ job on machine 1 & 8 & 7 & 1 \\
\hline $1^{\text {st }}$ job on machine 2 & 3 & 4 & 1 \\
\hline $2^{\text {nd }}$ job on machine 2 & 4 & 3 & 1 \\
\hline $3^{\text {rd }}$ job on machine 2 & 5 & 4 & 1 \\
\hline $4^{\text {th }}$ job on machine 2 & 4 & 5 & 1 \\
\hline
\end{tabular}

Total deviation $=8$

Best aspiration $=8$

Step-2: Tabu $=$ machine 2 job 3 speed. 
Step-3:

\begin{tabular}{|l|c|c|c|c|c|c|c|}
\hline & $\begin{array}{c}\text { Job } \\
\text { Sl. No. }\end{array}$ & $\begin{array}{c}\text { Machine } \\
\text { location }\end{array}$ & $\begin{array}{c}\text { Random } \\
\text { number }\end{array}$ & $\begin{array}{c}\text { Lower } \\
\text { speed }\end{array}$ & $\begin{array}{c}\text { Higher } \\
\text { speed }\end{array}$ & $\begin{array}{c}\text { Initial best } \\
\text { sequence }\end{array}$ & $\begin{array}{c}\text { Processing } \\
\text { speed }\end{array}$ \\
\hline & 1 & 1 & 0.2 & 5 & 8 & 5 & 7.4 \\
\hline & 2 & 1 & 0.3 & 7 & 10 & 7 & 9.1 \\
\hline & 3 & 1 & 0.3 & 3 & 7 & 4 & 5.8 \\
\hline & 4 & 1 & 0.2 & 7 & 10 & 8 & 9.4 \\
\hline & 1 & 2 & 0.4 & 2 & 7 & 3 & 5 \\
\hline Tabu & 2 & 2 & 0.2 & 3 & 7 & 4 & 6.2 \\
\hline & 3 & 2 & & 4 & 8 & 5 & 5 \\
\hline
\end{tabular}

Example for $7.4=$ random number*lower speed $+((1-$ random speed $) *$ higher speed $) 0$ $1^{\text {st }}$ job on machine 1

Start time $=0$

Finish time $=0+7.4=7.4$

$1^{\text {st }}$ job on machine 2

Start time $=7.4$

$1^{\text {st }}$ job completion time on machine $2=7.4+5=12.4$

$2^{\text {nd }}$ job on machine 1

Start time $=7.4$

Finish time $=7.4+9.1=16.5$

$2^{\text {nd }}$ job on machine 2

Start time $=16.5$

$2^{\text {nd }}$ job on machine 2

Finish time $=16.2+6.2=22.4$

Machine 1 maintenance

Starts $=16.5$

Finish time $=16.5+2=18.5$

$3^{\text {rd }}$ job on machine 1

Start time $=18.5$

$3^{\text {rd }}$ job on machine 1

Finish time $=18.5+5.8=24.3$

Machine 2 maintenance

Starts $=22.4$

Finishes $=22.4+3=25.4$

$3^{\text {rd }}$ job on machine 2

Start time $=25.4$

Finishes $=25.4+5=30.4$

$4^{\text {th }}$ job on machine 1

start time $=3^{\text {rd }}$ job on machine one finish time $=24.3$

Finish time $=24.3+9.4=33.7$

$4^{\text {th }}$ job on machine 2

Start time $=3^{\text {rd }}$ job on machine 2 finishes $=30.4$

Finish time $=30.4+5.4=35.8$

Make span $=35.8$

Aspiration criteria

Sum of process deviation

\begin{tabular}{|c|c|c|l|}
\hline Job list & Initial & Changed value & Deviation \\
\hline $1^{\text {st }}$ job on machine 1 & 5 & 7.4 & 2.4 \\
\hline $2^{\text {nd }}$ job on machine 1 & 7 & 9.1 & 2.1 \\
\hline $3^{\text {rd }}$ job on machine 1 & 4 & 5.8 & 1.8 \\
\hline $4^{\text {th }}$ job on machine 1 & 8 & 9.4 & 1.4 \\
\hline $1^{\text {st }}$ job on machine 2 & 3 & 5 & 2 \\
\hline $2^{\text {nd }}$ job on machine 2 & 4 & 6.2 & 2.2 \\
\hline $3^{\text {rd }}$ job on machine 2 & 5 & 5 & 0 \\
\hline $4^{\text {th }}$ job on machine 2 & 4 & 5.4 & 1.4 \\
\hline
\end{tabular}


Total deviation $=13.3$

Aspiration $=13.3$

Another example

\begin{tabular}{|c|c|c|l|c|c|c|c|}
\hline & $\begin{array}{c}\text { Job } \\
\text { Sl. No. }\end{array}$ & $\begin{array}{c}\text { Machine } \\
\text { location }\end{array}$ & $\begin{array}{c}\text { Random } \\
\text { number }\end{array}$ & $\begin{array}{c}\text { Lower } \\
\text { speed }\end{array}$ & $\begin{array}{c}\text { Higher } \\
\text { speed }\end{array}$ & $\begin{array}{c}\text { Initial best } \\
\text { sequence }\end{array}$ & $\begin{array}{c}\text { Processing } \\
\text { speed }\end{array}$ \\
\hline & 1 & 1 & 0.4 & 5 & 8 & 5 & 6.8 \\
\hline & 2 & 1 & 0.2 & 7 & 10 & 7 & 9.4 \\
\hline & 3 & 1 & 0.3 & 3 & 7 & 4 & 5.8 \\
\hline & 4 & 1 & 0.1 & 7 & 10 & 8 & 9.7 \\
\hline & 1 & 2 & 0.25 & 2 & 7 & 3 & 5.75 \\
\hline & 2 & 2 & 0.3 & 3 & 7 & 4 & 5.8 \\
\hline Tabu & 3 & 2 & & 4 & 8 & 5 & 5 \\
\hline & 4 & 2 & 0.25 & 3 & 6 & 4 & 5.25 \\
\hline
\end{tabular}

$1^{\text {st }}$ job on machine 1

Start time $=0$

Finish time $=0+6.8=6.8$

$1^{\text {st }}$ job on machine 2

Start time $=6.8$

Finish time $=6.8+5.75=12.55$

$2^{\text {nd }}$ job on machine 1

Start time $=12.55$

$2^{\text {nd }}$ job on machine 2

Finish time $=12.55+9.4=13.44$

Machine 1 maintenance

Start time $=13.44$

Finish time $=13.44+5.8=19.24$

Starts $=19.24$

Finish time $=19.24+2=21.24$

$3^{\text {rd }}$ job on machine 1

Start time $=21.24$

Finish time $=21.24+5.8=27.04$

Machine 2 maintenance

Starts $=19.24$

Finishes $=19.24+3=22.24$

$3^{\text {rd }}$ job starts on machine 2

Start time $=27.04$

Finishes $=27.04+5=32.04$

$4^{\text {th }}$ job on machine 1

Start time $=3^{\text {rd }}$ job on machine one finish time $=27.04$

$4^{\text {th }}$ job on machine 1

Finish time $=27.04+9.7=36.74$

$4^{\text {th }}$ job on machine 2

Start time $=36.74$

Finish time $=36.74+5.25=41.99$

Make span $=41.99$

Aspiration criteria

Sum of process deviation 


\begin{tabular}{|l|c|c|l|}
\hline Job list & Initial & Changed value & Deviation \\
\hline $1^{\text {st }}$ job on machine 1 & 5 & 6.8 & 1.8 \\
\hline $2^{\text {nd }}$ job on machine 1 & 7 & 9.4 & 2.4 \\
\hline $3^{\text {rd }}$ job on machine 1 & 4 & 5.8 & 1.8 \\
\hline $4^{\text {th }}$ job on machine 1 & 8 & 9.7 & 1.7 \\
\hline $1^{\text {st }}$ job on machine 2 & 3 & 5.75 & 2.75 \\
\hline $2^{\text {nd }}$ job on machine 2 & 4 & 5.8 & 1.8 \\
\hline $3^{\text {rd }}$ job on machine 2 & 5 & 5 & 0 \\
\hline $4^{\text {th }}$ job on machine 2 & 4 & 5.25 & 1.25 \\
\hline
\end{tabular}

Total deviation $=13.5$

Aspiration $=13.5$

Step-3: Say the tabu condition eliminated.

\begin{tabular}{|l|c|c|l|c|c|c|c|}
\hline & $\begin{array}{c}\text { Job } \\
\text { Sl. No. }\end{array}$ & $\begin{array}{c}\text { Machine } \\
\text { location }\end{array}$ & $\begin{array}{l}\text { Random } \\
\text { number }\end{array}$ & $\begin{array}{c}\text { Lower } \\
\text { speed }\end{array}$ & $\begin{array}{c}\text { Higher } \\
\text { speed }\end{array}$ & $\begin{array}{c}\text { Initial best } \\
\text { sequence }\end{array}$ & $\begin{array}{c}\text { Processing } \\
\text { speed }\end{array}$ \\
\hline & 1 & 1 & 0.7 & 5 & 8 & 5 & 5.9 \\
\hline & 2 & 1 & 0.9 & 7 & 10 & 7 & 7.3 \\
\hline & 3 & 1 & 0.7 & 3 & 7 & 4 & 4.2 \\
\hline & 4 & 1 & 0.75 & 7 & 10 & 8 & 7.75 \\
\hline & 1 & 2 & 0.6 & 2 & 7 & 3 & 4 \\
\hline $\begin{array}{l}\text { Tabu } \\
\text { deleted }\end{array}$ & 2 & 2 & 0.8 & 3 & 7 & 4 & 3.8 \\
\hline & 3 & 2 & 0.9 & 4 & 8 & 5 & 4.4 \\
\hline
\end{tabular}

$1^{\text {st }}$ job on machine 1

Start time $=0$

Finish time $=0+5.9=5.9$

$1^{\text {st }}$ job on machine 2

Start time $=5.9$

Finish time $=5.9+4=9.9$

$2^{\text {nd }}$ job on machine 1

Start time $=5.9$

Finish time $=5.9+7.3=13.2$

$2^{\text {nd }}$ job on machine 2

Start time $=13.2$

Finish time $=13.22+3.8=17.02$

Machine 1 maintenance

Starts $=13.2$

Finish time $=13.2+2=15.2$

$3^{\text {rd }}$ job on machine 1

Start time $=15.2$

Finish time $=15.2+4.2=19.4$

Machine 2 maintenance

Starts $=17.02$

Finishes $=17.02+3=20.02$

$3^{\text {rd }}$ job starts on machine 2

Start time $=20.02$

Finishes $20.02+4.4=24.42$

$4^{\text {th }}$ job on machine 1

Start time $=3^{\text {rd }}$ job on machine 1 finish time $=19.4$

Finish time $=19.4+7.75=27.15$

$4^{\text {th }}$ job on machine 2

Start time $=27.15$

Finish time $=27.15+4.2=31.35$ 
Make span $=31.35$

Aspiration criteria

Sum of process deviation

\begin{tabular}{|l|c|c|c|}
\hline Job list & Initial & Changed value & Deviation \\
\hline $1^{\text {st }}$ job on machine 1 & 5 & 5.9 & 0.9 \\
\hline $2^{\text {nd }}$ job on machine 1 & 7 & 7.3 & 0.3 \\
\hline $3^{\text {rd }}$ job on machine 1 & 4 & 4.2 & 0.2 \\
\hline $4^{\text {th }}$ job on machine 1 & 8 & 7.75 & 0.25 \\
\hline $1^{\text {st }}$ job on machine 2 & 3 & 4 & 1 \\
\hline $2^{\text {nd }}$ job on machine 2 & 4 & 3.8 & 0.2 \\
\hline $3^{\text {rd }}$ job on machine 2 & 5 & 4.4 & 0.6 \\
\hline $4^{\text {th }}$ job on machine 2 & 4 & 4.2 & 0.2 \\
\hline
\end{tabular}

Total deviation $=3.65$

Aspiration $=3.65$

Aspiration criteria acceptable if it is less than 4

Select the best sequence step-3e

\section{Diversification phase:}

Example for job 1 machine one original speed 7. Speed can vary between (6-10).

Range of speed change $=(10-6)=4$

Interval parameter $=$ random $(0,4)=2.1$

Upperval $=($ maxspeed - oldspeed + interval parameter $)=(10-7+2.1)=5.1$

Lower value $=($ minspeed - oldspeed + interval parameter $)=6-7+2.1=1.1$

Random coefficient $=$ random $($ upperval, abs $($ lowerval $))=\operatorname{random}(1.1,5.1)=3$

New processing speed of job $=$ random coefficient + original speed $=3+7=10$

If the speed is beyond range reperform it

Calculate all the speeds of all jobs

\begin{tabular}{|c|c|c|c|c|c|c|c|c|c|c|}
\hline $\begin{array}{c}\text { Job } \\
\text { Sl.No. }\end{array}$ & $\begin{array}{l}\text { Machine } \\
\text { location }\end{array}$ & $\begin{array}{l}\text { Initial } \\
\text { speeds }\end{array}$ & $\begin{array}{l}\text { Lower } \\
\text { speed }\end{array}$ & $\begin{array}{l}\text { Highe } \\
\mathbf{r} \\
\text { speed }\end{array}$ & Range & $\begin{array}{l}\text { Interval } \\
\text { parameter } \\
\text { S }\end{array}$ & $\begin{array}{c}\text { UppeI } \\
\text { val }\end{array}$ & $\begin{array}{c}\text { Lower } \\
\text { val }\end{array}$ & $\begin{array}{c}\text { Random } \\
\text { coefficien } \\
\mathbf{t}\end{array}$ & $\begin{array}{c}\text { New } \\
\text { processin } \\
\text { g speed }\end{array}$ \\
\hline 1 & 1 & 5 & 5 & 8 & 3 & 1.2 & 4.2 & 1.2 & 2.3 & 7.3 \\
\hline 2 & 1 & 7 & 7 & 10 & 3 & 1 & 4 & 1 & 1.3 & 8.3 \\
\hline 3 & 1 & 4 & 3 & 7 & 4 & 2.1 & 5.1 & 1.1 & 3 & 7 \\
\hline 4 & 1 & 8 & 7 & 10 & 3 & 1.3 & 3.3 & 0.3 & 1.8 & 9.8 \\
\hline 1 & 2 & 3 & 2 & 7 & 5 & 2.4 & 6.4 & 1.4 & 4 & 7 \\
\hline 2 & 2 & 4 & 3 & 7 & 4 & 2.6 & 5.6 & 1.6 & 3.1 & 7.1 \\
\hline 3 & 2 & 5 & 4 & 8 & 4 & 1.9 & 4.9 & 0.9 & 2.8 & 7.8 \\
\hline 4 & 2 & 4 & 3 & 6 & 3 & 2.1 & 4.1 & 1.1 & 1.8 & 5.8 \\
\hline
\end{tabular}




\section{RESULTS WITH DIFFERENT DATA SETS}

- The proposed GA algorithm is coded in $\mathrm{C}++$

- Dataset for processing times placed at annexure

- Result of two data set furnished below in the table

Table 1

\begin{tabular}{|c|c|c|c|c|c|c|c|c|c|}
\hline $\begin{array}{c}\text { No. of } \\
\text { machines }\end{array}$ & $\begin{array}{c}\text { No. } \\
\text { of } \\
\text { jobs }\end{array}$ & $\begin{array}{c}\text { Maintenance } \\
\text { time }\end{array}$ & $\begin{array}{c}\text { No. of } \\
\text { maintenance } \\
\text { activities/ } \\
\text { machine }\end{array}$ & $\begin{array}{l}\text { Forward } \\
\text { Schedule } \\
\text { sequence }\end{array}$ & \begin{tabular}{|c|} 
Makespan of \\
forward \\
schedule \\
(minutes)
\end{tabular} & $\begin{array}{c}\text { Makespan of } \\
\text { inverse } \\
\text { Schedule } \\
\text { Genetic } \\
\text { algorithm }\end{array}$ & $\begin{array}{l}\text { Minimum } \\
\text { Deviation } \\
\text { (minutes) }\end{array}$ & $\begin{array}{l}\text { Make span of } \\
\text { inverse } \\
\text { Schedule } \\
\text { (tabu } \\
\text { algorithm) } \\
\text { (minutes) }\end{array}$ & $\begin{array}{l}\text { Minimum } \\
\text { Deviation } \\
\text { (minutes) }\end{array}$ \\
\hline 20 & 20 & 30 & 4 & Seq 1 & 2608 & 2550 & 60 & 2600 & 120 \\
\hline 20 & 30 & 25 & 5 & Seq 2 & 3120 & 2980 & 110 & 3000 & 200 \\
\hline 30 & 20 & 30 & 4 & Seq 3 & 3140 & 3090 & 120 & 3112 & 180 \\
\hline 30 & 30 & 25 & 5 & Seq 4 & 3830 & 3810 & 155 & 3820 & 230 \\
\hline
\end{tabular}

Seq 1:

Job serial no.: $1,2,3,4,5,6,7,8,9,10,11,12,13,14,15,16,17,18,19,20$

Job sequence: $4,5,8,10,2,6,14,19,17,13,16,12,18,3,20,9,15,11,7,1$ Seq 2:

Job serial no.: 1, 2, 3, 4, 5, 6, 7, 8, 9, 10, 11, 12, 13, 14, 15, 16, 17, 18, 19, 20, 21, 22, 23, $24,25,26,27,28,29,30$

Job sequence: $4,5,23,8,28,26,10,2,6,14,30,29,19,17,27,25,13,16,12,24,18,3$, $20,9,15,22,11,7,1,21$

Seq 3:

Job serial no.: $1,2,3,4,5,6,7,8,9,10,11,12,13,14,15,16,17,18,19,20$

Job sequence: $4,5,8,14,2,6,19,10,17,13,16,9,18,3,20,1,15,11,7,12$ Seq 4:

Job serial no.: 1, 2, 3, 4, 5, 6, 7, 8, 9, 10, 11, 12, 13, 14, 15, 16, 17, 18, 19, 20, 21, 22, 23, $24,25,26,27,28,29,30$

Job sequence: $8,5,23,14,28,26,10,2,6,1,18,29,16,17,27,25,13,12,30,24,19,3,20$, $9,15,22,11,7,4,21$

\subsection{Interpretation of result}

Makespan of inverse scheduling is not compromised and the sequence remains the same. The adjustment of process parameters realizes the inverse scheduling, which is the practical requirement

\subsection{Comparison between two algorithms}

Once the expected makespan of each instance has been obtained for each algorithm, the best solution obtained for each instance of same size is selected and it is called best value of instance. With this, calculated the relative percentage deviation (RPD) with respect to this best solution with the following expression:

$\mathrm{RPD}=($ average value of instance - best value of instance $) /$ average value $* 100$ 
where average value of instance is average of all expected make span attained for considered instances. RPD help us to compare algorithms because the RPD values denote relative distance of average algorithm solution from best solution obtained for special instance, clearly, lower values of RPD are preferred.

Table 2 Average RPD values

\begin{tabular}{|c|c|c|}
\hline $\begin{array}{c}\text { Instance } \\
\text { (machines *jobs) }\end{array}$ & GA & TABU \\
\hline $20 * 20$ & 2.42 & 2.5 \\
\hline $20 * 30$ & 2.62 & 3 \\
\hline $30 * 20$ & 4.3 & 4.4 \\
\hline $30 * 30$ & 4.5 & 5.1 \\
\hline
\end{tabular}

\section{CONCLUSIONS}

In this paper, multi -machine inverse scheduling problem with make span time minimization is explored and suggested a heuristic to solve Firstly, a mathematical model is constructed and a genetic algorithm is employed to solve this problem. The experimental results show that the proposed method can generate satisfactory solutions and has achieved significant improvement.

Extensive research has not been been done concerning multi criteria problems in ISP. ISP is also very important because it can effectively improve existing manufacturer system and optimally allocate resources.

\section{FUTURE SCOPE OF THE STUDY}

Most existing models on ISP consider minimally perturbing the job processing time with common criteria, such as makespan, without considering machine stoppages, other criterias such as earliness, tardiness etc. with machine stoppages can also be studied further.

\section{REFERENCES}

[1] Ahuja R. K. and Orlin, J. B. "Inverse optimization", Operations Research, Vol. 49, No. 5, pp. 771-783, 2001.

[2] Martorell, S., Sánchez, A., Carlos, S., et al., Comparing effectiveness and efficiency in technical specifications and maintenance optimization. Reliability Engineering \& System Safety, 77(3):281-289. [doi:10.1016/S0951-8320(02)00061-3], 2002.

[3] Wang L. and Zheng D. Z., "An effective hybrid heuristic for flow shop scheduling", International Journal of Advanced Manufacturing Technology, Vol. 21, No. 1, pp. 38-44, 2003.

[4] Heuberger, C., "Inverse combinatorial optimization: A survey on problems, methods, and results," Journal of Combinatorial Optimization, Vol. 8, No. 3, pp. 329-361, 2004.

[5] Koulamas, C., "Inverse scheduling with controllable job parameters", International Journal of Services and Operations Management, Vol. 1, pp. 35-43, 2005.

[6] Chen R. J., Chen F., and. Chun, T.G., "Inverse problems of a single machine scheduling to minimize the total completion time," Journal of Shanghai Second Polytechnic University, Vol. 22, No. 2, pp. 1-7, 2005.

[7] Liu L. and Zhang, J., "Inverse maximum flow problems under the weighted Hamming distance," Journal of Combinatorial Optimization, Vol. 12, No. 4, pp. 395-408, 2006.

[8] Liu L.L., Ng, C.T. and Cheng, T.C.E., "Bi criterion scheduling with equal processing times on a batch processing machine," Computers \& Operations Research, Vol. 36, No. 1, pp. 110-118, 2009. 
[9] Chen R.J. and Tang, G.C., "Inverse problems of supply chain scheduling and flowshop scheduling," Operations Research and Management Science, Vol. 18, No. 2, pp. 80-84, 2009.

[10] Brucker. P. and Shakhlevich, N.V., "Inverse scheduling with maximum lateness objective," Journal of Scheduling, Vol. 12, No. 5, pp. 475-488, 2009.

[11] Berrichi A., Amodeo L., Yalaoui F., Chatelet E., \& Mezghiche M., "Bi-objective optimization algorithms for joint production and maintenance scheduling: application to the parallel machine problem", Journal of Intelligent Manufacturing, 20, pp. 389-400, 2009.

[12] Fattahi P. and Fallahi, A., "Dynamic scheduling in flexible jobshop systems by considering simultaneously efficiency and stability," CIRP Journal of Manufacturing Science and Technology, Vol. 2, No. 2, pp. 114-123, 2010.

[13] Moradi E., \& Zandieh M., "Minimizing the makespan and the system unavailability in parallel machine scheduling problem: a similarity-based genetic algorithm", Intelligent Journal of Advanced Manufacturing Technology, 51 pp. 829-840, 2010.

[14] Brucker, P. and Shakhlevich, N.V., "Inverse scheduling: two machine flow-shop problem," Journal of Scheduling, Vol. 14, No. 3, pp. 239-256, 2011.

[15] Pham H. and Lu X., "Inverse problem of total weighted completion time objective with unit processing time on identical parallel machines", Journal of East China University of Science and Technology, Vol. 38, No. 6, pp. 757-761, 2012.

[16] Ahmad, R., Kamaruddin, S., An overview of time-based and condition-based maintenance in industrial application, Computers \& Industrial Engineering, 63(1):135-149, 2012.

[17] Aissi H., Bazgan C., and Vanderpooten, D., "General approximation schemes for min- max (regret) versions of some (pseudo) polynomial problems," Discrete Optimization, Vol. 7, No. 3, pp. 136-148, 2010.

[18] Ganesan T., Elamvazuthi I., Shaari, K. Z. K and Vasant P., "Swarm intelligence and gravitational search algorithm for multi-objective optimization of synthesis gas production," Applied Energy, Vol. 103, pp. 368-374, 2013.

[19] Vasant, P., "Hybrid LS-SA-PA methods for solving fuzzy nonlinear programming problems", Mathematical and Computer Modelling, Vol. 57, No. 1-2, pp. 180-188, 2013.

[20] Kim B. S. and. Joo C.M., "Single-machine total completion time scheduling with positionbased deterioration and multiple rate-modifying activities," Industrial Engineering Management Systems, Vol. 10, No. 4, pp. 247-254, 2011.

[21] Liu P. and Tian X., "Two-agent single-machine scheduling with resource-dependent starting times," Mathematical Problems in Engineering, Vol. 2013, Article ID 805261, 5 pages, 2013.

[22] Li D.C., Hsu P.-H., and. Chang C.-C, "A genetic algorithm-based approach for singlemachine scheduling with learning effect and release time," Mathematical Problems in Engineering, Vol. 2014, Article ID249493, 12 pages, 2014.

[23] Hongtruong P and Xiwen L., "The inverse parallel machine scheduling problem with minimum total completion time", Vol. 10, No. 2, pp. 613-620, 2014.

[24] Wang S. \& Liu M., "Two-stage hybrid flow shop scheduling with preventive maintenance using multi-objective tabu search method", International Journal of Production Research, 52(5) pp. 1495-1508, 2014.

[25] Cui, W.W., Lu, Z., and Pan, E., "Integrated production scheduling and maintenance policy for robustness in a single machine", Computers \& Operations Research, 47 pp. 81-91, 2014.

[26] Batun S. and Azizolu M., "Single machine scheduling with preventive maintenances," International Journal of Production Research, Vol. 47, No. 7, pp. 1753-1771, 2009. 
[27] Elamvazuthi, I. Vasant P., and Ganesan, T., "Hybrid optimization techniques for optimization in a fuzzy environment," Intelligent Systems Reference Library, Vol. 38, pp. 1025-1046, 2013.

[28] Glover F., Tabu search, ORSA Journal on Computing 1989, Vol. 1, No. 3.

[29] Reeves. C., A genetic algorithm for flow shop sequencing. Computers and Operations Research, 1995, 22: 5-13.

[30] Wang, L.Z., "Cutting plane algorithms for the inverse mixed integer linear programming problem", Operations Research Letters, Vol. 37, No. 2, pp. 114-116, 2009. 